\title{
过渡金属催化端炔的氧化交叉偶联反应研究进展
}

$\begin{array}{llllll}\text { 张聪霞 } & \text { 李娜娜 } & \text { 李 兴 常宏宏 } & \text { 刘 强 魏文珑* } \\ & \text { (太原理工大学 } & \text { 化学化工学院生物与制药工程系 } & \text { 太原 030024) } & \end{array}$

\begin{abstract}
摘要 炔基化合物是有机合成中重要的一类官能团化合物，端基炔通过氧化交叉偶联反应可以制备各种各样新的炔基 化合物. 总结了近年来端基炔参与的氧化交叉偶联反应，主要介绍了 $\mathrm{Pd}, \mathrm{Cu}, \mathrm{Fe}$ 等过渡金属催化的端炔氧化交叉偶联反 应研究进展.
\end{abstract}

关键词 过渡金属; $\mathrm{C}-\mathrm{H}$ 键；端基炔；氧化交叉偶联；进展

\section{Progress in Transition-Metal-Catalyzed Oxidative Cross-Coupling of Terminal Alkynes}

\author{
Zhang, Congxia Li, Nana Li, Xing Chang, Honghong Liu, Qiang Wei, Wenlong* \\ (College of Chemistry and Chemical Engineering, Taiyuan University of Technology, Taiyuan 030024)
}

\begin{abstract}
Alkynyl compounds are one kind of important functional compounds in organic synthesis. Various new alkynyl compounds can be obtained via oxidative cross-coupling reactions of terminal alkynes. Recent oxidative cross-coupling reactions involving terminal alkynes are reviewed. The advances of cross-coupling reactions catalyzed by $\mathrm{Pd}, \mathrm{Cu}, \mathrm{Fe}$ and so on are particularly described.
\end{abstract}

Keywords transition metal; $\mathrm{C}-\mathrm{H}$ bond; terminal alkyne; oxidative cross-coupling; progress

在有机合成中, 构建 $\mathrm{C}-\mathrm{X}(\mathrm{X}=\mathrm{C}, \mathrm{O}, \mathrm{N}, \mathrm{S}$, etc. $)$ 键 具有重要的意义 ${ }^{[1,2]}$. 传统有机合成中, 新的 $\mathrm{C}-\mathrm{C}$ 键是 通过过渡金属催化的方法把两个功能化的底物进行偶 联来形成 ${ }^{[3 \sim 7]}$. 随着 “原子经济性” 和绿色化学概念的 出现, 通过碳氢键活化的方法把两个未预先官能化而活 化的底物经过脱氢偶联起来以构建 $\mathrm{C}-\mathrm{C}$ 键的方法正越 来越引起化学家们的兴趣 ${ }^{[8 \sim 12]}$, 并且, 在这方面人们已 经取得了很多成果. 2003 年, McGill 大学的李朝军 ${ }^{[13,14]}$ 首先提出交叉脱氢偶联 $(\mathrm{CDC})$ 的概念, 即直接利用不同 反应底物中的 $\mathrm{C}-\mathrm{H}$ 键在氧化条件下进行交叉偶联反应 形成新的 $\mathrm{C}-\mathrm{C}$ 键(Eq. 1). 交叉脱氢偶联反应不需要使 用带有活化官能团的反应底物, 因而省去了一步甚至多 步制备官能团化反应底物的步骤, 进而实现了更短的合 成路线和更高的效率, 为直接利用简单原料进行高效复 杂的有机合成任务提供了一条新的思路和途径 ${ }^{[15]}$.

$$
\mathrm{C}_{1}-\mathrm{H}+\mathrm{H}-\mathrm{C}_{2} \underset{[\mathrm{O}]}{\stackrel{\text { cat. } \mathrm{M}}{\longrightarrow}} \mathrm{C}_{1}-\mathrm{C}_{2}
$$

在氧化碳氢键活化反应中, 用金属催化剂来活化碳 氢键以进行偶联反应最为常见, 这其中的金属催化剂包 括贵金属催化剂(如钯、铑、铱等)以及铜、铁等便宜的 金属催化剂. 根据文献报道 ${ }^{[13,16]}$, 这两类催化剂对碳氢 键活化反应的作用机理是不一样的, 贵金属催化剂催化 的碳氢键活化主要是贵金属对 $\mathrm{C}-\mathrm{H}$ 键的氧化加成起了 主要作用, $\mathrm{Cu}, \mathrm{Fe}$ 等金属催化剂则更多是在与氧化剂作 用时起到电子转移的作用, 对 $\mathrm{C}-\mathrm{H}$ 键的氧化加成几乎 是不可能的.

炔基是在众多天然产物、生物活性化合物、有机材 料以及各种合成中间体中常见的一种官能团 ${ }^{[17]}$. 用金 属催化炔烃参与的偶联反应在将炔基官能团引入到有 机分子的方法中起到很重要的作用, 最近, 金属催化末 端炔烃的氧化交叉偶联已经成为一种制备各种取代炔 烃的很有效的新方法. 1869 年, Glaser ${ }^{[18,19]}$ 首次发现了铜 催化炔烃的氧化自偶联反应，尽管最近几年，金属催化 端基炔与其它亲核试剂的氧化交叉偶联已经取得了很

\footnotetext{
*E-mail: weiwenlong@tyut.edu.cn

Received July 20, 2013; revised September 3, 2013; published online September 17, 2013.

Project supported by the Natural Science Foundation of Shanxi Province (Nos. 2012021007-2, 2011011010-2), and the Scientific and Technological Innovation Programs of Higher Education Institutions in Shanxi Province (No. 20120006).

山西省自然科学基金(Nos. 2012021007-2, 2011011010-2)及山西省高等教育机构科技创新(No. 20120006)资助项目.
} 
大的进步，并且不断开发出一些新的有效的方法，但是， 这些方法要想得到广泛应用仍然具有很大的挑战, 主要 是由于难以克服需氧条件下炔的自偶联. 本文将基于不 同催化体系对近年来端基炔参与的氧化交叉偶联研究 进展进行简要综述.

\section{Pd 催化}

\section{1 空气或氧气作氧化剂}

Chang 课题组 ${ }^{[20]} 2011$ 年报道了唑类杂环化合物与 端基炔的氧化偶联(Eq. 2). 当使用 $\mathrm{Pd}\left(\mathrm{PPh}_{3}\right)_{4}$ 作催化剂 时, 反应在氧化性较弱的空气中进行比在氧气中进行收 率较高; 其它的钯盐催化剂即使在 $\mathrm{PPh}_{3}$ 存在下, 反应收 率也相对较低; 同时, 他们发现使用二乙酸碘苯或者叔 丁基过氧化氢作氧化剂时收率也较低. 如果增加唑类化 合物和碱 $(t-\mathrm{BuOLi})$ 的当量值, 可以提高反应收率. 反应 广普性研究表明带有供电子基的芳基炔得到了中等到 较好的收率(67\% 88\%), 而带有吸电子基的端炔偶联 产物收率稍有降低 $(50 \% \sim 64 \%)$, 重要的是脂肪族端炔 如 1-环已烯炔、环已炔和三异丙基乙炔基硅烷分别在该 反应条件下取得了 $67 \%, 41 \%$ 和 31\%的收率, 然而链状 衍生物如 1-辛炔仅得到了少于 $5 \%$ 的收率.

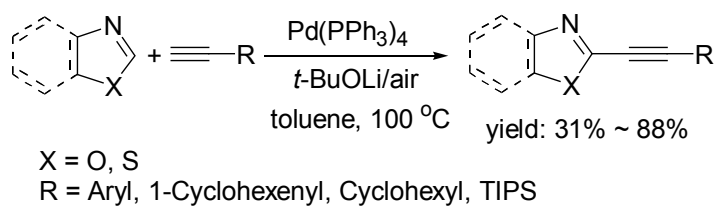

在 Sonogashira 交叉偶联反应中, 通常把钯、膦配体 和碘化亚铜结合起来作催化剂; 然而, 很多膦配体对空 气敏感, 并且比较昂贵, 碘化亚铜的存在又容易形成炔 基铜化合物导致炔发生自偶联反应. 为了克服这些缺 点, 一些没有膦配体和碘化亚铜参与的钯催化 Sonogashira 交叉偶联反应已经逐渐发展起来.

Yang 课题组 ${ }^{[21]} 2005$ 年报道了芳基碘与端基炔的 Sonogashira 交叉偶联, 该反应没有铜盐和配体参与, 在 氧气条件下 $\mathrm{PdCl}_{2}(1 \mathrm{~mol} \%)$ 作催化剂, 吡咯烷作碱进行 (Eq. 3); 对于缺电子的芳基碘于 $25{ }^{\circ} \mathrm{C}$ 下就可以实现反 应, 其它碘代芳烃则需要相对较高的反应温度才能得到 中等到高的收率 $(65 \% \sim 97 \%)$. 该方法缺点是原料仅限 于芳香碘, 并且反应需要相对较高的催化剂用量(1 $\mathrm{mol} \%$ ).

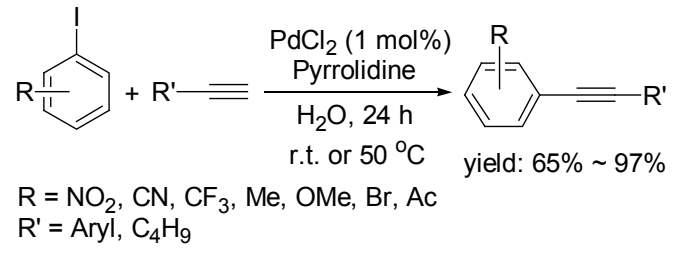

同年, $\mathrm{Li}$ 课题组 ${ }^{[2]}$ 进一步使用 $0.01 \sim 2 \mathrm{~mol} \%$ 的 $\mathrm{Pd}(\mathrm{OAc})_{2}$ 作催化剂, 三乙烯二胺(DABCO)作碱, 在空气 中实现了芳基磑和芳基溴与端基炔的交叉偶联(Eq. 4). 反应广普性研究表明无论含有供电子基还是吸电子基 的芳基碘均以中等到较好的收率获得产物 (55\% $100 \%$ ); 作者把此催化体系应用到芳基澳的反应中，主 要针对对硝基澳苯和溴苯进行了考察, 结果活性有明显 下降，若炔的用量从 1.2 equiv.增加到 1.8 equiv.时，对硝 基溴苯才可达到 $90 \%$ 的收率，而溴苯只得到痕量产物.

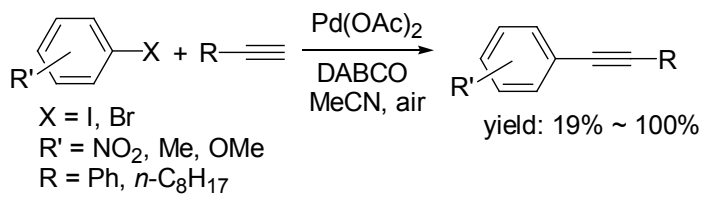

Jung 课题组 ${ }^{[23]} 2009$ 年报道了第一例氧化钯催化端 基炔与烯烃的类 Heck 偶联反应(Eq. 5). 如用 $\mathrm{Pd}_{2}(\mathrm{dba})_{3}$ 和 $\mathrm{PdCl}_{2}\left(\mathrm{PPh}_{3}\right)_{2}$ 作催化剂时, 得到的大部分是炔自偶联 产物, 若用 $\operatorname{Pd}\left(\mathrm{PPh}_{3}\right)_{4}$ 作催化剂时, 反应无法进行; 当用 $\mathrm{Pd}(\mathrm{OAc})_{2}$ 作催化剂对碱进行篮选时, 发现无机碱得到交 叉偶联产物与自偶联产物的比例比有机碱较高, 但仍没 有得到较好的结果. 最后经过篎选, 确定 Pd(TFA) 2 作催 化剂, $\mathrm{O}_{2}$ 作氧化剂, $\mathrm{K}_{2} \mathrm{CO}_{3}$ 作碱为最优条件, 主要生成 (E)-式烯炔的交叉偶联产物, 取得了较好的选择性和收 率( $25 \%$ \% $92 \%$ ). 反应广普性研究表明带有供电子基的 芳基炔收率较高. 他们认为端基炔质子的酸度在产物组 成中起了一定作用，含有较少酸性质子的化合物比含有 更多酸性质子的化合物能提供更好的选择性; 如果增加 反应底物的酸性可以更快地形成活泼的钯炔中间体，进 而容易进行自偶联反应; 相反, 酸性较弱的反应底物不 活泼，形成钯基炔中间体时速度较慢，与烯烃反应具有 更好的选择性并顺利生成理想的交叉偶联产物，该反应 的机理可以用 Heck 偶联反应机理解释.

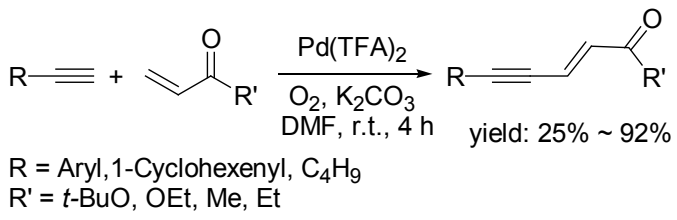

Lei 课题组 ${ }^{[24]}$ 于 2010 年报道了使用 $\mathrm{Pd}(\mathrm{dba})_{2}$ 作催化 剂, 空气为氧化剂时端基炔与烷基锌试剂的氧化交叉偶 联(Eq. 6). 当标准底物苯乙炔与正丁基氯化锌在干燥的 空气或氧气中反应时, 几乎都生成了炔的二聚物, 交叉 偶联产物很少; 而当把一氧化碳与空气以体积比 $1: 10$ 在室温下混合后，交叉偶联产物的收率达到了 $91 \%$, 并 且表现出令人满意的选择性(96\%). 很显然,一氧化碳 在该反应中起到至关重要的作用，经推测，一氧化碳是 作为 $\pi$-酸配体来促进 $\mathrm{C}(\mathrm{sp})-\mathrm{C}\left(\mathrm{sp}^{3}\right)$ 的还原消除 ${ }^{[25]}$. 底物 
扩展表明: 无论芳香炔还是脂肪炔均取得了中等到较好 的收率(66\% 93\%), 其中位阻效应对反应收率影响也 不大, 如邻位、间位和对位取代的甲氧基苯乙炔收率分 别是 $86 \%, 84 \%$ 和 $81 \%$.

$$
\begin{aligned}
& \mathrm{R}^{1} \stackrel{\mathrm{E}}{=}+\mathrm{R}^{2} \mathrm{ZnX} \underset{\mathrm{air} / \mathrm{CO}(\mathrm{V}: \mathrm{V}=10: 1), \text { r.t. }}{\stackrel{\left.[\mathrm{dba})_{2}\right](5 \mathrm{~mol} \%)}{=}} \mathrm{R}^{1}=\mathrm{R}^{2} \\
& \mathrm{R}^{1}=\text { Aryl, alkneyl, alkyl, TES } 66 \% \sim 93 \% \\
& \mathrm{R}^{2}=\text { primary, secondary alkyl }
\end{aligned}
$$

吲哚及其衍生物是许多天然产物和药物的重要结 构单元, 具有特殊的生物活性. 合成吲哚炔基类化合物, 具有代表性的工作是 $\mathrm{Pd}^{0}$ 催化卤代吲哚与端基炔的传统 Heck-Cassar-Sonogashira (HCS) 反应 ${ }^{[26 ~ 28]}($ Eq.7), 或者吲 哚与卤代端基炔的直接偶联反应 ${ }^{[29 \sim 31]}$ (Eq.8).

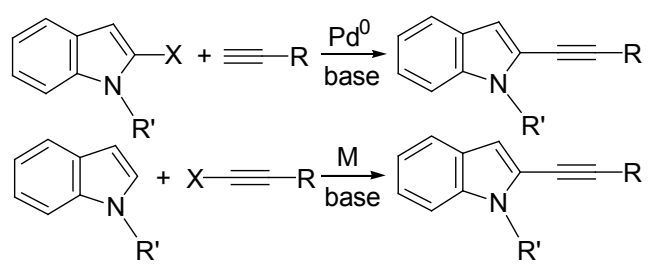

李朝军课题组 ${ }^{[32]} 2010$ 年报道了 $\mathrm{K}_{2} \mathrm{PdCl}_{4}$ 在 $\mathrm{O}_{2}$ 环境 下催化端基炔与吲哚衍生物的氧化 HCS 反应(Eq. 9). 反 应中为了抑制炔发生自偶联, 将炔溶解在 DMSO 中, 再 用注射器缓慢加入到反应体系中. 对反应底物范围的考 察发现：对位上带有供电子基的芳香炔取得了 $62 \%$ $73 \%$ 的收率, 带有吸电子基的芳香炔收率稍有降低 (47\% 51\%); 脂肪炔如三异丙基乙炔基硅烷也取得了 $72 \%$ 的收率, 而 1-癸炔收率较低, 只有 $15 \%$, 可能是由 于反应中产生的相应炔基钯中间体亲电性较弱. 反应机 理研究表明碱 $\mathrm{Cs}_{2} \mathrm{CO}_{3}$ 中和特戊酸 $(\mathrm{PivOH})$ 后产生的 CsOPiv 与 $\mathrm{Pd}^{\mathrm{II}}$ 和端炔作用产生中间体炔基二价钯化合 物, 它再与吲哚衍生物发生亲核取代反应生成另一中间 体，此中间体经过 CsOPiv 去质子化产生一新的中间体， 这一新的中间体最后经过还原消除生成了目标产物. 该 反应体系与传统的 HCS 反应相比有以下特点: (1)不需 要预先制备卤代吲哚或炔基卤; (2)仅需要催化量的碱; (3)使用一种绿色氧化剂一氧气. 该反应为端炔与其它芳 烃的氧化 HCS 偶联提供了依据.

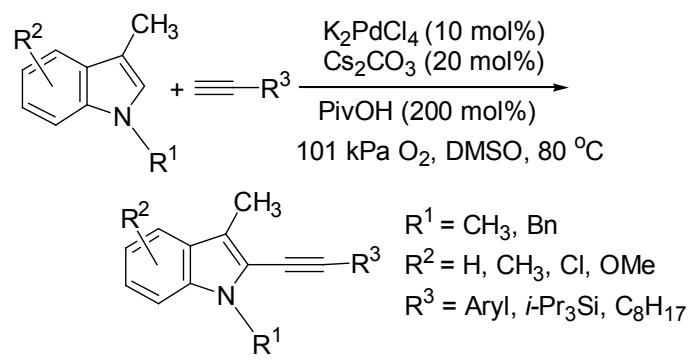

yield: $15 \% \sim 73 \%$

\section{$1.2 \mathrm{Ag}$ 化合物作氧化剂}

最近, 过渡金属银作为氧化剂促进两个亲核试剂之 间的氧化交叉偶联反应已经成为构建有机化学中化学 键的一种新方法. Zou 课题组 ${ }^{[33]}$ 于 2003 年以 $\mathrm{PdCl}_{2}$ (dppf) 作催化剂, $\mathrm{Ag}_{2} \mathrm{O}$ 为氧化剂, $\mathrm{K}_{2} \mathrm{CO}_{3}$ 作碱, 在溶剂 $\mathrm{CH}_{2} \mathrm{Cl}_{2}$ 中于室温下完成了芳基硼酸与各种端基炔的交叉偶联 (Eq. 10). 反应广普性研究表明: 脂肪族端炔与芳基硼酸 以 $78 \% \sim 90 \%$ 的收率得到交叉偶联产物, 苯乙炔与苯硼 酸反应得到的产物收率较低( $30 \%$ ). 该反应体系的缺点 是催化剂用量较大 (5 mol\%). 最后，作者还对该反应的 机理进行了推测，结果如下：芳基硼酸或原位生成的炔 基银首先将催化物种前体 $\operatorname{Pd}(\mathrm{II})$ 还原成 $\operatorname{Pd}(0)$, 循环 1 和 循环 2 都从端炔 $\mathrm{C}-\mathrm{H}$ 键对 $\mathrm{Pd}(0)$ 产物的氧化加成开始, 紧接着分别经过嗍或炔的转金属化形成不同的中间体 $\mathbf{A}$ 和 $\mathbf{B}$, 所以循环 1 和 2 之间存在着竞争, 循环 1 获得 交叉偶联产物，而循环 2 得到炔自偶联产物(Scheme 1). 当来自硼的转金属化不如来自炔的转金属化快时，自偶 联产物将生成. 在该反应机理中 $\mathrm{Ag}_{2} \mathrm{O}$ 的作用可能是活 化炔基钯配合物，这样就可以促进来自芳基硼酸的芳基 转金属化.
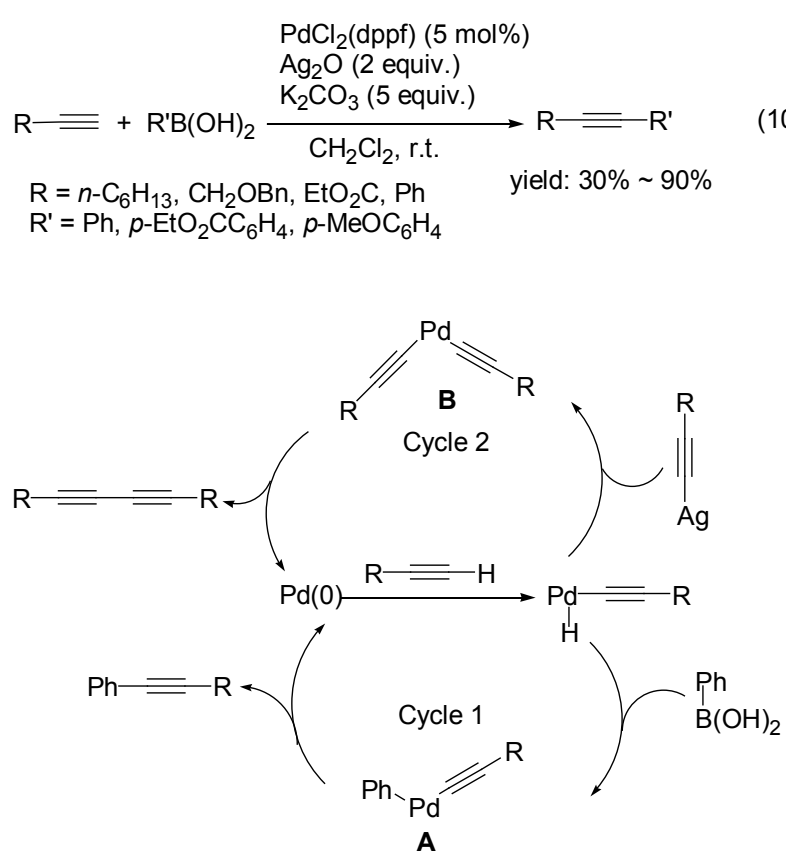

Scheme 1

2007 年, $\mathrm{Wu}$ 课题组 ${ }^{[34]}$ 用二茂铁亚胺环钯 Cat* 1 作 催化剂, $\mathrm{Ag}_{2} \mathrm{O}$ 为氧化剂, 在氮气保护下实现了芳基硼酸 或芳基硼酸酯与端基炔的交叉偶联(Eq. 11), 该体系使 用的催化剂量较少 (1 mol\%). 底物广普性研究表明带有 供电子基和吸电子基的芳基炔均以较好的收率获得产 物(71\% 88\%); 脂肪炔中含有羟基的 2-甲基-3-丁炔-2- 
醇仅取得了 $20 \%$ 的收率(由于炔的活性低于芳基硼酸时, 主要得到硼酸的自偶联产物), 其余脂肪炔获得了 $63 \% \sim 90 \%$ 的收率.

$$
\begin{aligned}
& \mathrm{ArB}(\mathrm{OH})_{2}+\mathrm{R}=\frac{\mathrm{Cat}^{*} \text { 1, } \mathrm{KOAC}}{\mathrm{Ag}_{2} \mathrm{O}, \mathrm{CH}_{2} \mathrm{Cl}_{2}} \mathrm{Ar}=\mathrm{R} \\
& \mathrm{R}=\text { Aryl, COOEt, } \mathrm{CH}_{3}\left(\mathrm{CH}_{2}\right)_{4}, \mathrm{CH}_{3}\left(\mathrm{CH}_{2}\right)_{5} \text {, } \\
& \mathrm{CH}_{3}\left(\mathrm{CH}_{2}\right)_{7}, \mathrm{C}\left(\mathrm{CH}_{3}\right)_{2} \mathrm{OH} \\
& \mathrm{Cl}_{\mathrm{CPh}}^{\mathrm{C}} \\
& \text { Cat }{ }^{*} 1
\end{aligned}
$$

Cheng 课题组 ${ }^{[35]} 2009$ 年报道了芳基三甲氧基硅烷 与端基炔的交叉偶联(Eq.12). 该反应用 $\mathrm{PdCl}_{2}$ (dppf)作催 化剂, $\mathrm{AgF}$ 作氧化剂, $\mathrm{NaHCO}_{3}$ 为碱, 在干燥的溶剂 $\mathrm{CH}_{3} \mathrm{CN}$ 中进行, 对一系列反应底物如芳香与各种脂肪 族的炔，产物收率在 $38 \% \sim 99 \%$ 之间。在传统的 Sonogashira 反应中, 缺电子的炔不能发生反应或者能 得到产物, 但收率偏低, 然而该反应体系缺电子的炔如 丙炔酸乙酯可提供 76\%的收率.

$$
\begin{aligned}
& \mathrm{ArSi}(\mathrm{OMe})_{3}+\mathrm{R} \rightleftharpoons \frac{\mathrm{PdCl}_{2}(\mathrm{dppf}), \mathrm{AgF}}{\mathrm{NaHCO}_{3}, \mathrm{CH}_{3} \mathrm{CN}} \underset{\text { yield: } 38 \% \sim 99 \%}{\mathrm{Ar}}=\mathrm{R} \\
& \mathrm{R}=\mathrm{Ph}, \mathrm{COOEt}, \mathrm{Bn}, \mathrm{CH}_{2} \mathrm{OH}, \mathrm{CH}_{2} \mathrm{NEt}_{2}, \mathrm{CH}(\mathrm{OEt})_{2}
\end{aligned}
$$

Larock 课题组 ${ }^{[36]} 2011$ 年报道了 $N$-取代悉尼酮与端 基炔的氧化交叉偶联(Eq. 13). 该反应体系用 $\mathrm{Pd}(\mathrm{OAc})_{2}$ 作催化剂, $\mathrm{CuCl}_{2}$ 作添加剂, $\mathrm{Ag}_{2} \mathrm{O}$ 为氧化剂, 而且此反应 必须严格在空气中进行, 在氮气保护下没有反应发生. 为了减少炔自偶联产物的生成, 反应需将炔分批加入反 应体系, 或者更理想地是用注射泵缓慢注射炔到反应体 系中来降低炔的浓度. 反应广普性研究表明苯乙炔取代 基的电子效应对反应没有太大的影响，无论带有供电子 基还是吸电子基的苯乙炔均取得了 $66 \%$ 78\%的收率; 杂环炔烃 2-乙炔基噻吩仅以 38\%的收率生成交叉偶联 产物, 脂肪炔烃丙炔酸甲酯也获得较低的收率(33\%).

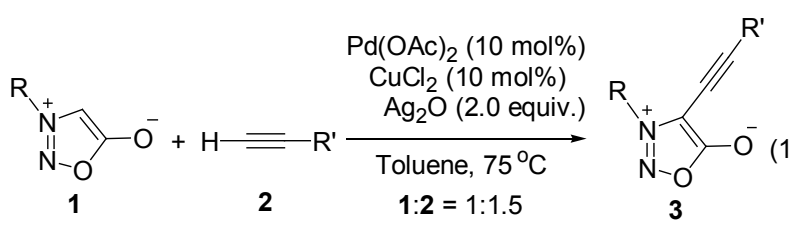

$$
\begin{aligned}
\mathrm{R}= & \mathrm{Ph}, 4-\mathrm{ClC}_{6} \mathrm{H}_{4}, 4-\mathrm{BrC}_{6} \mathrm{H}_{4}, 4-\mathrm{MeC}_{6} \mathrm{H}_{4}, \quad \text { yield: } 29 \% \sim 78 \% \\
& 4-\mathrm{O}_{2} \mathrm{NC}_{6} \mathrm{H}_{4}, 3,4-\mathrm{OCH}_{2} \mathrm{OC}_{6} \mathrm{H}_{3}, \mathrm{Me} \\
\mathrm{R}^{\prime}= & \mathrm{Ph}, 4-\mathrm{MeC}_{6} \mathrm{H}_{4}, 3-\mathrm{MeOC}_{6} \mathrm{H}_{4}, 4-\mathrm{AcC}_{6} \mathrm{H}_{4},
\end{aligned}
$$$$
\text { 3- } \mathrm{CIC}_{6} \mathrm{H}_{4}, 2 \text {-Thiophenyl, } \mathrm{CO}_{2} \mathrm{Me}
$$

$\mathrm{Su}$ 课题组 ${ }^{[37]} 2013$ 年报道了五元杂环芳香族化合物 与端炔的交叉偶联(Eq. 14). 该反应体系用 $\mathrm{Pd}_{2}(\mathrm{dba})_{3}$ 作 催化剂, $\mathrm{Ag}_{2} \mathrm{O}$ 作氧化剂, $\mathrm{Cs}_{2} \mathrm{CO}_{3}, \mathrm{Et}_{3} \mathrm{~N}$ 和特戊酸( $\left.\mathrm{PivOH}\right)$
为添加剂, 其中, 特戊酸的存在可以减少炔的二聚化. 对底物扩展的研究表明: 带有吸电子基和供电子基的芳 香炔均能以 $55 \% \sim 73 \%$ 的收率得到理想产物，脂肪族的 炔得到的产物很少. 他们提出了一种可能的氧化交叉偶 联反应机理，该反应催化剂 $\operatorname{Pd}$ 用量少是与生成的不溶 性炔基银衍生物有关，由于在反应过程中，炔基银也充 当了固体支撑物的作用, 这样可以避免中间过渡态 $\mathrm{Pd}^{0}$ 凝结形成不活泼的 $\operatorname{Pd}$ 黑. 另外, 在该反应体系中不溶性 的炔基银衍生物是缓慢释放出炔基基团的，从而抑制了 炔的自偶联发生.

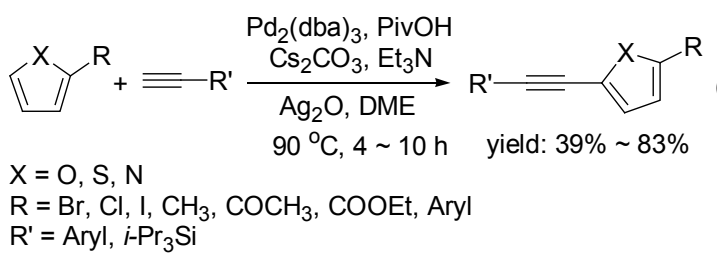

\section{3 其它氧化剂}

Wang 课题组 ${ }^{[38]} 2011$ 年报道了用 $\operatorname{Pd}(\mathrm{OAc})_{2}$ 作催化 剂催化各种对甲苯磺酰酮腙或重氮甲酸酯与端炔合成 共轭烯炔的反应(Scheme 2). 经过篮选确定, 苯醌(BQ) 作氧化剂效果最好，同时作者考察了不同配体对反应的 影响, 发现配体 $\mathrm{P}(2 \text {-furyl })_{3}$ 以相对较好的结果得到理想 产物, 当 $\mathrm{P}(2 \text {-furyl })_{3}$ 与 $\mathrm{Pd}(\mathrm{OAc})_{2}$ 的比例从 $2: 1$ 增加到 4: 1 时, 反应效果更好. 底物广普性研究表明: 位阻效 应对底物收率影响不大，邻位、间位和对位取代的对甲 苯磺酰酩腙以中等的收率获得产物( $53 \% \sim 77 \%)$, 对甲 苯磺酰酮腙的芳香环上带有吸电子基团时反应收率比 带有供电子基团时收率稍高 $10 \%$ 左右，而整体收率在 $53 \% \sim 71 \%$ 之间. 该反应是炔基迁移插入钯卡宾以高选 择性的方式获得共轭烯炔.
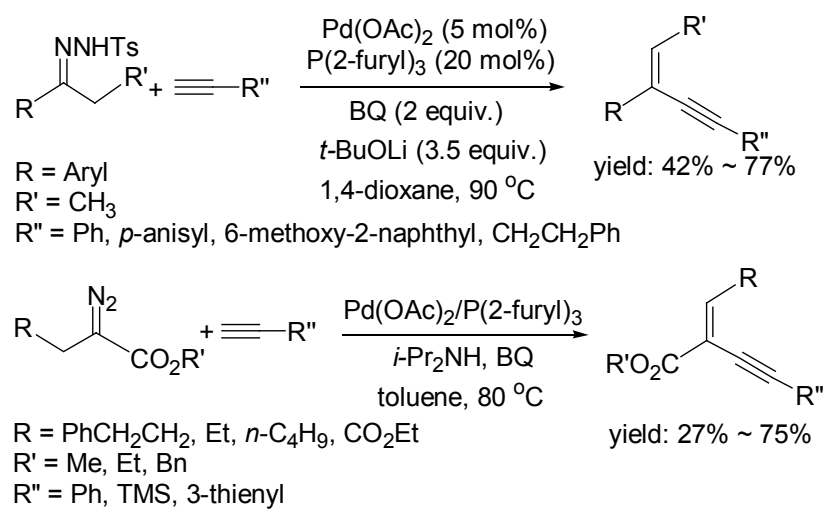

Scheme 2

\section{$2 \mathrm{Cu}$ 催化}

\section{1 空气或氧气作氧化剂}

2008 年, Stahl 课题组 ${ }^{[39]}$ 报道了氮亲核试剂(仲胺或 
磺酰胺)与端基炔在 $\mathrm{O}_{2}$ 条件下偶联生成炔氨基化合物的 反应(Eq. 15). 分别对在 DMSO 中 2 equiv. 的 $\mathrm{CuCl}_{2}$ 和在 甲苯中 $20 \mathrm{~mol} \% \mathrm{CuCl}_{2}$ 的催化效果进行了考察, 结果发 现使用后者作催化体系催化反应时以中等和较好的收 率得到炔氨基化合物，最后确定最优条件是 $20 \mathrm{~mol} \%$ $\mathrm{CuCl}_{2}$ 作催化剂, 各 2 equiv.的 $\mathrm{Na}_{2} \mathrm{CO}_{3}$ 和吡啶分别作碱 和配体, 溶剂为甲苯. 对反应广普性研究发现带有吸电 子基的炔如丙炔酸乙酯和对硝基苯乙炔分别获得 $\leqslant 10 \%$ 和 35\%的收率，而带有供电子基的端炔以中等到 较好的收率获得产物(51\% 97\%).

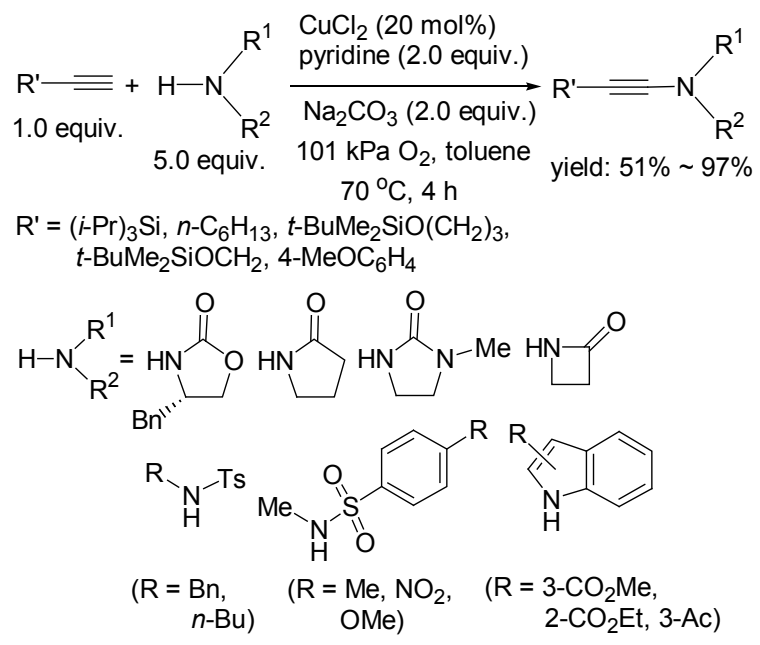

2013 年, Bolm 课题组 ${ }^{[40]}$ 在 Stahl 研究的基础上用二 氧六环代替甲苯作溶剂(因为原料更易溶于二氧六环), 在其它条件不变的情况下完成砜亚胺与端基炔的氧化 交叉偶联(Eq. 16). 对反应广普性研究发现无论带有供 电子基还是吸电子基的芳基炔都得到了中等到较好的 收率 $(48 \% \sim 84 \%)$; 然而, 生成的某些产物在用硅胶层 析柱分离时易分解, 几乎全部转化为 $N$-酰基砜亚胺.

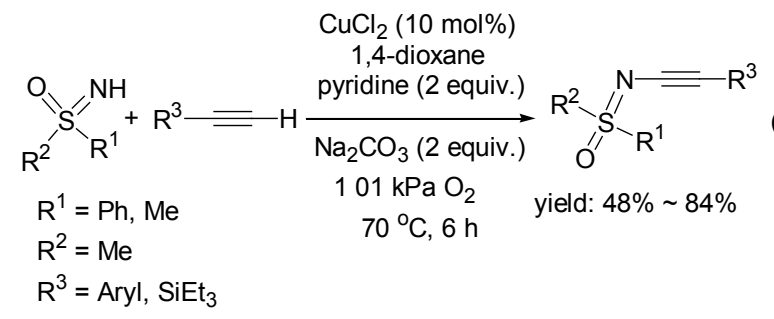

2010 年, Su 课题组 ${ }^{[41]}$ 报道了第一例铜催化芳烃 C $\mathrm{H}$ 键活化与端炔的直接炔基化反应(Eq. 17). 该反应体 系用 $\mathrm{CuCl}_{2}$ 作催化剂, 1,10-邻菲咯啉 (1,10-phenanthroline)作配体, 氧气为氧化剂, 强碱 $t$ - BuOLi 取代弱碱 $\mathrm{NaHCO}_{3}$ 和 $\mathrm{K}_{3} \mathrm{PO}_{4}$ 作碱; 反应体系中若加入添加剂 DDQ (2,3-二氧基-5,6-二氯对苯二醌)时, 产物收率得到提高 并且抑制了炔的自偶联, 这可能是由于 DDQ 作为电子 传递中介促进了催化剂的需氧再氧化. 反应广普性研究
表明：带有供电子基的端基炔取得了 42\% 74\%的收 率，而带有吸电子基的端炔收率稍有降低(30\% 69\%).
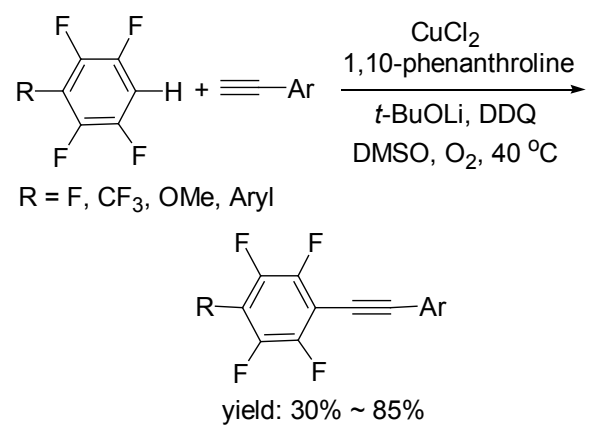

2010 年, Miura 课题组 ${ }^{[2]}$ 报道了多氟取代的芳烃与 端基炔的 $\mathrm{C}-\mathrm{H}$ 键活化偶联, 反应是在 $\mathrm{Cu}(\mathrm{OTf})_{2} / t$ BuOLi/1,10-邻菲咯啉体系于室温下空气中进行的, 采 用的溶剂是 DMSO (Eq. 18). 其中, $\mathrm{Cu}(\mathrm{OTf})_{2}$ 作催化剂, $t$-BuOLi 用作碱, 1,10 -邻菲咯啉作配体. 反应广普性研 究表明: 带有供电子基的炔可得到中等的收率 $68 \%$ $76 \%$ ), 而带有吸电子基的炔得到相对较低的收率 (25\% 54\%), 如对甲酯基的炔收率只有 25\%.

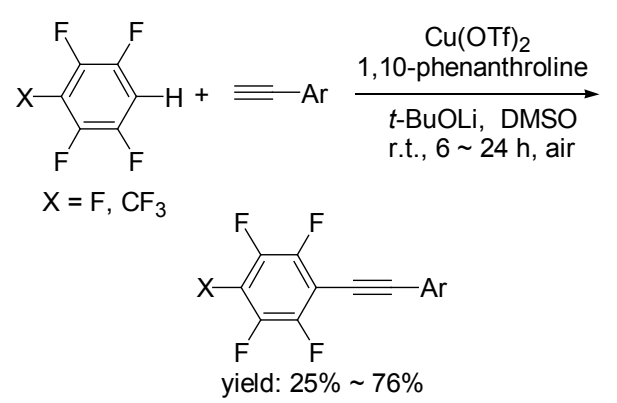

含 $\mathrm{C}-\mathrm{P}$ 键的有机膦化合物在有机合成、有机功能 材料和药物中应用广泛, 其中 1-炔基膦酸酯更是一类重 要的有机合成中间体, 而使用过渡金属催化法来构建 C-P 键是最简单易行的方法之一, 最常用的制备 1-炔 基膦酸酯的方法是通过炔格氏试剂或锂试剂与氯代磷 酸酯反应，而这一传统方法对反应物的官能团有太多限 制, 且需无水无氧 ${ }^{[43,44]} .2009$ 年, Zhao 课题组 ${ }^{[45]}$ 报道了 以廉价的 $\mathrm{Cu}$ 盐 $\left[\mathrm{CuI}\right.$ 和 $\left.\mathrm{Cu}(\mathrm{OAc})_{2} \cdot \mathrm{H}_{2} \mathrm{O}\right]$ 作催化剂, 空气作 氧化剂氧化下在 DMSO 溶剂中实现由简单稳定的亚磷 (膦)酸酯与端基炔偶联获得 1-炔基膦酸酯(Eq. 19). 广普 性研究表明: 脂肪炔与芳香炔均以较高的收率获得产物 (83\% 99\%). 该方法反应条件温和、操作简单、绿色经

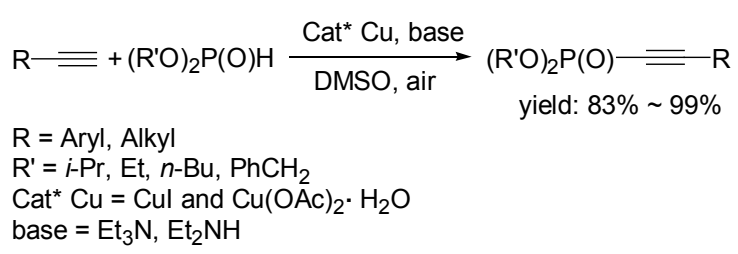


济(副产物是水)、底物适用性广，是目前合成 1-炔基膦 酸酯最简单、最经济有效的方法, 有着广阔的应用前景, 必将极大地推动炔基膦酸酯化学的发展.

Miura 课题组 ${ }^{[46]}$ 于 2010 年报道了 1,3,4-噁二唑和㤠 唑分别与端基炔的交叉偶联(Scheme 3). 反应用 $\mathrm{CuCl}_{2}$ 作催化剂, 氧气为氧化剂, $\mathrm{Na}_{2} \mathrm{CO}_{3}$ 作碱, $\mathrm{DMAc}$ 和 DMSO 分别作溶剂, 分别于 120 和 $150{ }^{\circ} \mathrm{C}$ 下反应, 芳香 族炔的产物取得中等的收率 $(43 \% \sim 66 \%)$, 脂肪族的炔 也能发生反应, 取得了 $42 \% \sim 74 \%$ 的收率, 若增大炔末 端烷基基团, 产物收率将会增加; 而反应在空气或氮气 中进行缓慢或者没有反应发生.
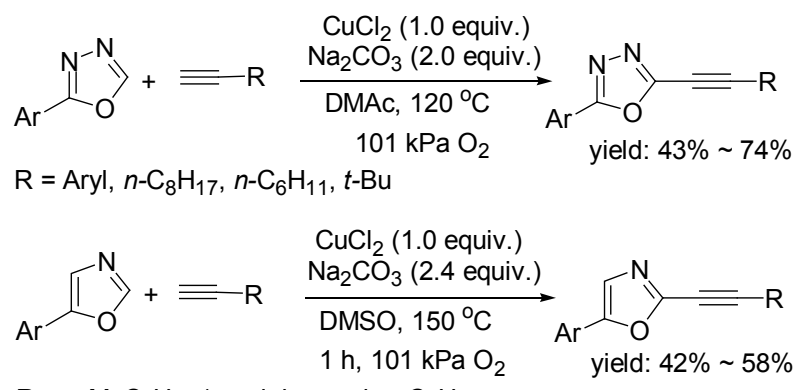

$\mathrm{R}=p-\mathrm{MeC}_{6} \mathrm{H}_{4}, 1$-cyclohexenyl, $n-\mathrm{C}_{8} \mathrm{H}_{17}$

\section{Scheme 3}

2010 年, Qing 课题组 ${ }^{[47]}$ 报道了第一例 $\mathrm{CuI}$ 催化三氟 甲基三甲基硅烷与端基炔的 $\mathrm{C}_{\mathrm{sp}}-\mathrm{C}_{\mathrm{sp}} 3$ 偶联反应(Eq. 20). 该反应以 1,10-邻菲咯啉充当配体, 空气作氧化剂, $\mathrm{KF}$ 作碱在 $\mathrm{DMF}$ 溶剂中于 $100^{\circ} \mathrm{C}$ 条件下进行. 若用氧气取代 空气, 只有炔的自偶联产物生成, 他们推测是因为生成 的 $\mathrm{CuCF}_{3}$ 过渡态产物在高浓度的氧气中失去了活性. 对 反应的广普性研究表明芳香炔和脂肪炔均以中等和较 好的收率得到相应的产物( $47 \% \sim 91 \%)$, 带有供电子和 吸电子基团的芳香炔收率均较好.

$$
\begin{aligned}
& \mathrm{R}=+\mathrm{Me}_{3} \mathrm{SiCF}_{3} \frac{\text { Cul, 1,10-phenanthroline }}{\mathrm{KF}, \mathrm{DMF}, 100{ }^{\circ} \mathrm{C} \text {, air }} \mathrm{R}=\mathrm{CF}_{3} \\
& \mathrm{R}=\text { Aryl, } \mathrm{PhCH}_{2} \mathrm{CH}_{2}, \mathrm{PhCH}_{2} \mathrm{~N}\left(\mathrm{CH}_{3}\right) \mathrm{CH}_{2} \quad \text { yield: } 47 \% \sim 91 \%
\end{aligned}
$$

\section{2 其它氧化剂}

2004 年, $\mathrm{Li}$ 课题组 ${ }^{[8]}$ 首次报道了用 $\mathrm{CuBr}$ 作催化剂, 过氧叔丁醇(TBHP)作氧化剂完成氮原子邻位的 $\mathrm{sp}^{3}$ 杂化 $\mathrm{C}-\mathrm{H}$ 键与炔烃的 $\mathrm{sp}$ 杂化 $\mathrm{C}-\mathrm{H}$ 键脱氢偶联直接合成丙 炔胺的反应(Eq. 21). 作者认为反应经过胺的单电子转 移和脱质子过程形成亚胺正离子; 亚胺与铜催化剂配 位，进一步与端炔发生偶联反应. 当使用 $\mathrm{N}$ 取代的四氢 异喹啉骨架化合物作反应底物时, 反应选择性地发生在 芐基位的 $\mathrm{C}-\mathrm{H}$ 键上. 反应广普性研究表明: 芳香炔以 相对较好的收率获得产物( $60 \% \sim 82 \%)$, 而脂肪炔获得 产物收率相对较低 $(12 \% \sim 58 \%)$. 该体系的缺点是反应 需要在三级甲胺的氮上有芳基或者三级胺的氮上有苄
基取代来诱导偶联的发生.

$$
\begin{aligned}
& \mathrm{CuBr}(5 \mathrm{~mol} \%) \\
& \mathrm{Ar}-\mathrm{N}^{\prime}+\equiv \mathrm{R} \stackrel{t-\mathrm{BuOOH}(1.0 \sim 2.0 \text { equiv. })}{100^{\circ} \mathrm{C}, 3 \mathrm{~h}} \mathrm{Ar}-\mathrm{N}^{\prime}=\mathrm{R}
\end{aligned}
$$

$\mathrm{Ar}=\mathrm{Ph}, 4-\mathrm{MeC}_{6} \mathrm{H}_{4}, 2-\mathrm{MeC}_{6} \mathrm{H}_{4}, 4-\mathrm{BrC}_{6} \mathrm{H}_{4}$

\section{$\mathrm{R}=\mathrm{Ph}, 4-\mathrm{MeC}_{6} \mathrm{H}_{4}, 4-\mathrm{MeOC}_{6} \mathrm{H}_{4}, 4-\mathrm{BrC}_{6} \mathrm{H}_{4}, 4-\mathrm{PhC}_{6} \mathrm{H}_{4}$,} 2-Py, $\mathrm{HOCH}_{2}, \mathrm{EtCO}_{2} \mathrm{CH}_{2}, \mathrm{CH}_{3} \mathrm{OCO}, \mathrm{Bu}$

2008 年，他们 ${ }^{[49]}$ 又成功地将该反应用于多肽衍生 物的合成中, 反应使用 $\mathrm{CuBr}$ 作催化剂, 过氧叔丁醇 (TBHP)作氧化剂, 在氩气环境中促使不同结构的 $N$-对 甲氧基苯基甘氨酸酰胺与苯乙炔反应，可以进一步得到 较好收率的甘氨酸酰胺衍生物. 产物经过还原氢化、脱 对甲氧基苯基等简单操作就可以很有效地合成苯丙氨 酸的衍生物(Scheme 4), 该类化合物是一种非常重要的 血管紧张素转换酶抑制剂的合成前体.

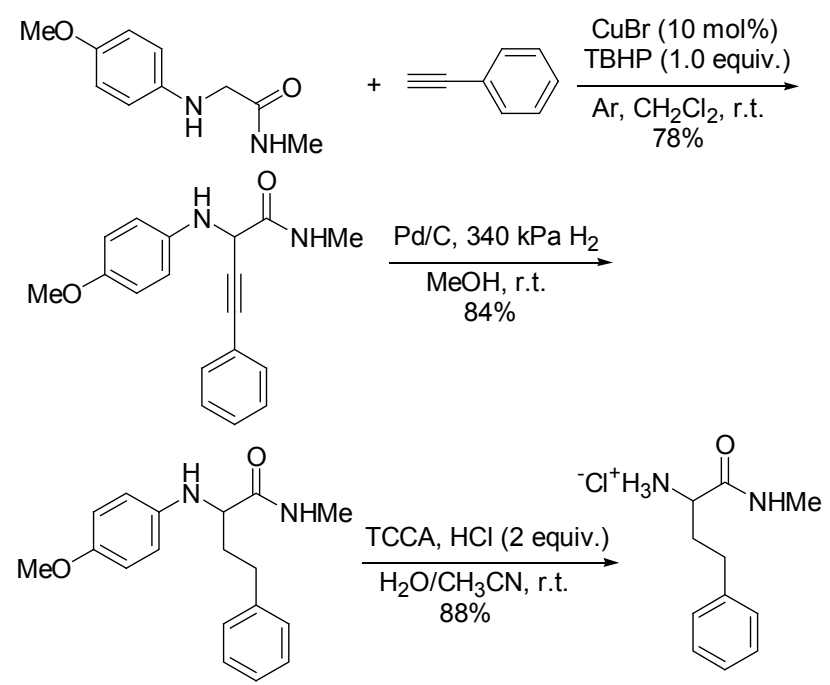

Scheme 4

2009 年, 该课题组 ${ }^{[50]}$ 又报道了用叔丁基过氧化物 作氧化剂, 四甲基乙二胺(TMEDA)作配体, $\mathrm{CuBr}$ 作催化 剂在甲苯溶剂中于 $110{ }^{\circ} \mathrm{C}$ 下催化 $\alpha$-氨基酸与端炔的脱 翔偶联反应(Eq. 22). 反应广普性研究表明, 芳香炔和脂 肪炔均以较好的收率获得产物( $74 \% \sim 95 \%)$; 对于不成 环且没有 $\alpha$-取代基的链状氨基酸, 如 2-二芐基氨基乙酸 只取得了 39\%的收率.

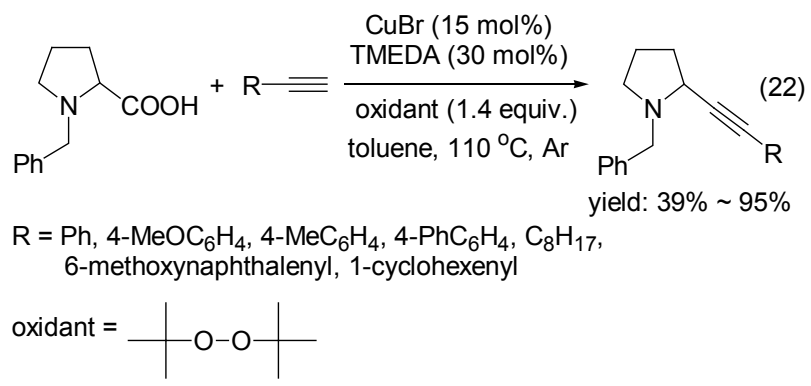


2008 年, $\mathrm{Fu}$ 课题组 ${ }^{[51]}$ 还发展了叔胺中氮上甲基的 炔基化反应(Eq. 23). 利用 $N$-溴代丁二酰亚胺(NBS)作为 氧化剂或自由基引发剂, 在 $\mathrm{CuBr}$ 催化作用下得到了三 级胺甲基的 $\mathrm{sp}^{3} \mathrm{C}-\mathrm{H}$ 活化中间体与端炔偶联的产物. 对反应物的广普性研究发现脂肪族叔胺的位阻效应对 产物收率有很大影响, 如 $N, N$-二甲基芐胺以 $61 \%$ 的收率 得到产物, 而位阻大的 $N, N$-二甲基环已胺收率只有 $29 \%$; 芳香族炔比脂肪族炔的反应活性好, 可以达到 $40 \% \sim 65 \%$ 的中等收率. 然而, 总体来说, 大部分产物 收率都相对较低 $(29 \% \sim 65 \%)$.

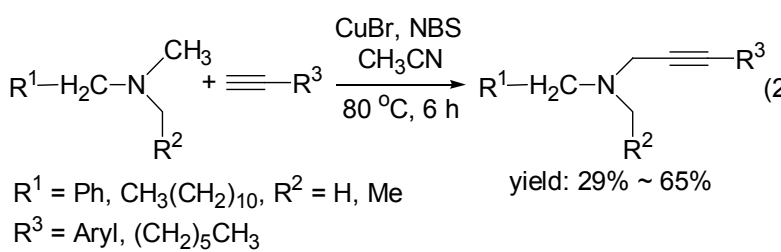

2009 年, Cheng 等 ${ }^{[52]}$ 报道了没有配体参与的 $\mathrm{CuI}$ 在 氧化剂 $\mathrm{Ag}_{2} \mathrm{O}$ 存在下催化芳基嗍酸与端炔的交叉偶联 (Eq. 24). 该反应体系中, 碱的种类起着很大的作用, 使 用 $\mathrm{Cs}_{2} \mathrm{CO}_{3}$ 时, 收率最高为 $80 \%$. 正如所预期的, 含有供 电子基和吸电子基的芳基硼酸在最优条件下反应效果 都较好，取得了 $45 \% \sim 88 \%$ 的收率. 然而，芳基硼酸的 位阻效应对反应有很大影响，如：对甲基、间甲基和邻 甲基取代的芳香硼酸参与反应时分别得到产物的收率 是 74\%，57\%和 45\%. 作者还基于以前报道的机理推测 该反应机理如下: 首先端炔与铜反应生成炔铜(I) 4, 炔 铜 4 经过 $\mathrm{Ag}_{2} \mathrm{O}$ 的氧化变为三价炔铜 $\mathbf{5}$, 紧接着 5 与芳基 硼酸通过转金属化反应产生中间体 6 , 最后, 6 经过还原 消除得到了交叉偶联产物 3 和一价铜(Scheme 5).
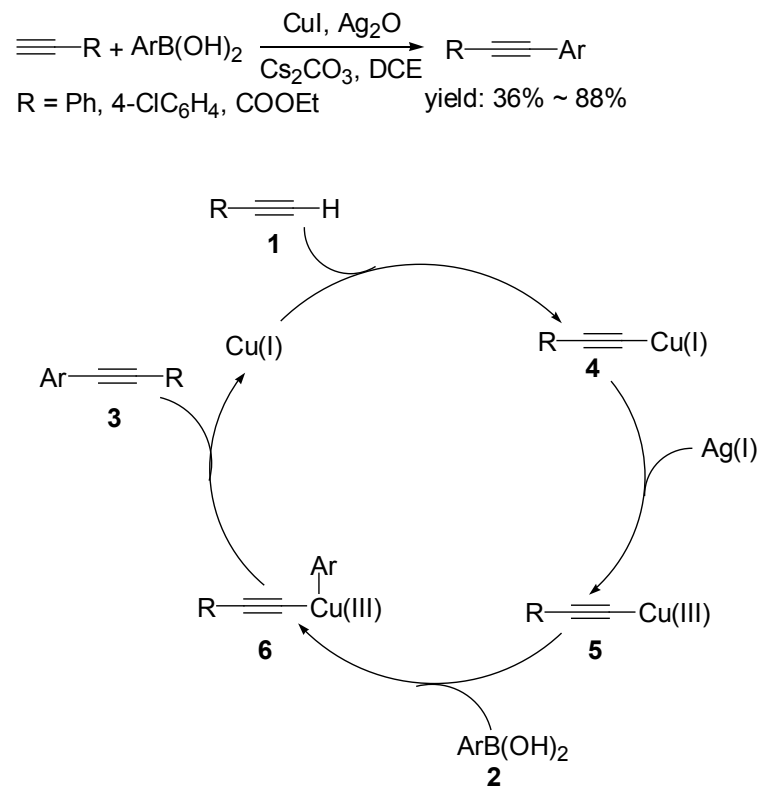

2012 年, Qing 课题组 ${ }^{[53]}$ 报道了第一例二氟甲基膦 酸酯三甲基硅烷与端炔的直接氧化交叉偶联反应(Eq. 25). 起初作者用他们课题组 ${ }^{[47]}$ 早期报道的铜催化三氟 甲基三甲基硅烷与端炔的反应条件，结果没得到目标产 物; 即使降低反应温度，得到的仍然是二氟甲基膦酸酯 三甲基硅烷的分解产物和炔的自偶联产物. 紧接着, 在 原有催化剂的基础上, 对氧化剂和碱进行笁选, 发现用 叔丁醇钾 ( $t$-BuOK) 和 2,3-二氰基-5,6-二氯对苯二醌 (DDQ)分别作碱和氧化剂时收率较好. 铜盐和配体在该 反应中是必须的, 而且为了得到较高收率的产物, 加料 方式也要严格控制，应将二氟甲基膦酸酯三甲基硅烷注 入到 $\mathrm{CuI}, 1,10$-邻菲咯啉, $t$-BuOK 和 $\mathrm{DMF}$ 在 $-15{ }^{\circ} \mathrm{C}$ 的 混合物中，接下来加入炔和 DDQ; 如果将所有试剂一 起混合反应，则没有产物生成. 该反应体系的优点是: (1)官能团兼容性较好; (2)条件温和.广普性研究表明无 论带有吸电子基团还是供电子基团的芳香炔均以中等 收率得到产物( $44 \% \sim 65 \%)$, 脂肪炔如 1-庚炔也取得了 40\%的收率.

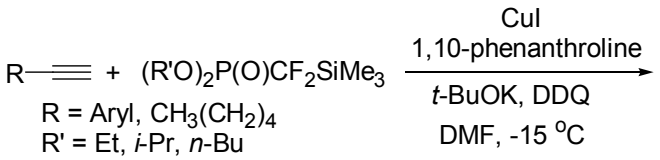

$$
\begin{aligned}
& \mathrm{R}=\mathrm{CF}_{2} \mathrm{P}(\mathrm{O})(\mathrm{OR})_{2} \\
& \text { yield: } 40 \% \sim 69 \%
\end{aligned}
$$

\section{3 无氧化剂}

铜或铁催化剂催化 $\mathrm{N}$ 上至少含有一个甲基的叔胺 合成炔丙基胺的直接氧化炔基化反应已有报道，反应中 使用外加的氧化剂对含有醛基基团的炔反应不利，因为 传统的氧化剂很容易将醛基氧化为羧基.

2009 年, $\mathrm{Li}$ 课题组 ${ }^{[54]}$ 也报道了三级胺的甲基位(N 上必须至少有一个 $\mathrm{CH}_{3}$ 存在)与端基炔的偶联反应(Eq. 26). 该反应在 $\mathrm{CuI}$ 催化和偶氮二羧酸乙酯(DEAD)作用 下于四氢呋喃溶剂中得到新的 $\mathrm{C}-\mathrm{C}$ 偶联产物, 该偶联 反应操作简单, 无需除水除氧, 也无需加入其它氧化剂, 反应条件温和. 反应广普性研究表明带有吸电子基和供 电子基的芳香炔均取得了中等到较好的收率(69\% 90\%), 脂肪炔如 1-已炔和苯乙基乙炔也分别以 $82 \%$ 和 $73 \%$ 的收率得到产物.

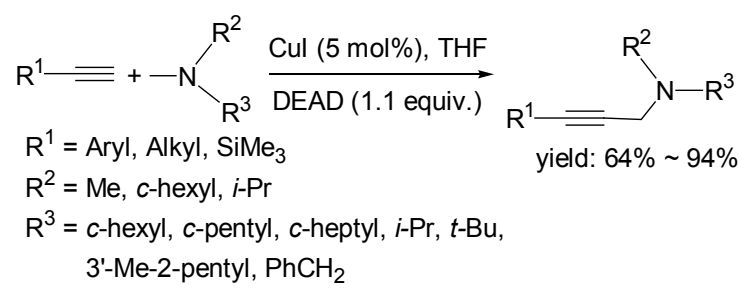

Scheme 5 
2011 年, $Y u$ 课题组 ${ }^{[55]}$ 报道了不使用外加氧化剂, 用 $\mathrm{Cu}(\mathrm{acac})_{2}$ 作催化剂催化甲基叔胺氮氧化物与端基炔偶 联合成丙炔胺的方法(Eq. 27). 该反应在 $\mathrm{N}_{2}$ 保护下在 DME 溶剂中于 $110{ }^{\circ} \mathrm{C}$ 下进行, 对底物扩展表明脂肪炔 以中等和较好的收率合成了相应的产物 (53\% 89\%), 而以前用铜催化甲基叔胺合成丙炔胺反应的报道中, 脂 肪炔的活性较低; 同时对于带有酯基、羟基和醛基的脂 肪族炔也都可顺利参与反应，收率在 $67 \% \sim 76 \%$ 之间; 带有供电子基的芳香炔收率高于带有吸电子基的芳香 炔, 其中吸电子诱导能力强的芳香炔收率低于吸电子能 力弱的, 如对溴苯乙炔收率为 $80 \%$, 而对氟苯乙炔收率 为 $68 \%$.

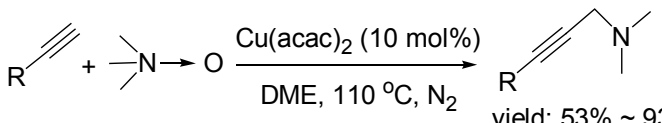

$$
\begin{aligned}
& \mathrm{R}=\text { Aryl, Alkyl, cyclohexyl }
\end{aligned}
$$

\section{Fe 催化}

铁催化剂具有无毒和价廉易得等优点, 因此, 发展 铁催化剂催化的有机合成反应具有环境友好和潜在的 工业应用价值. 铁催化剂在传统的 Gif 化学 ${ }^{[56]}$ 和 Feton 化学 ${ }^{[57]}$ 中氧化反应有着很广泛的应用, 但主要局限在 碳杂键的形成, 如 $\mathrm{C}-\mathrm{O}$ 键和 $\mathrm{C}-\mathrm{N}$ 键. 因此, 实现 $\mathrm{Fe}$ 催化氧化交叉偶联构筑 $\mathrm{C}-\mathrm{C}$ 键具有重要的理论意义和 应用价值.

2009 年, Vogel 课题组 ${ }^{[58]}$ 报道了以 $\mathrm{FeCl}_{2} /(t-\mathrm{BuO})_{2}$ 为 体系于 $100{ }^{\circ} \mathrm{C}$ 无溶剂条件下, $\mathrm{N}$ 上至少含有一个甲基的 叔胺与端基炔(包括芳基炔和三乙基乙炔基硅烷)进行氧 化偶联生成胺的炔基衍生物的方法(Scheme 6). 当用乙 炔基三乙基硅烷作为炔基化试剂时，通过 TBAF 对三乙 基硅烷丙炔胺脱三乙基硅烷保护后, 再进行一次 $\mathrm{C}-\mathrm{C}$ 键偶联反应, 即可得到炔基不对称二取代产物. 研究发 现用 $N, N$-二甲基对甲苯胺和苯乙炔作为标准底物, $\mathrm{FeCl}_{2}$ 作催化剂, $(t-\mathrm{BuO})_{2}$ 作氧化剂, 在氮气保护的条件 下, 产物收率仅为 $69 \%$, 反应在空气中进行, 产物收率 则可以达到 $88 \%$, 而如果反应在纯氧气条件下进行, 产 物收率反而下降. 他们认为可能是由于氧气造成了自由 基猝灭, 进而阻碍了反应的进行. 反应广普性研究表明 当 $N, N$-二甲基苯胺带有取代基时, 无论是芳香炔还是脂 肪炔与其反应均以中等到较好的收率获得产物 $(47 \%$ $93 \%$; 而当 $N, N$-二甲基苯胺不含取代基时，与芳香炔反 应收率则较低 $(24 \% \sim 32 \%)$, 与脂肪炔的反应文中没有 报道. 作者基于 Horner 的机理 ${ }^{[59]}$ 推测该反应机理如下: 首先, 没有端炔的存在下, 叔胺与 $\mathrm{FeCl}_{2} /(t-\mathrm{BuO})_{2}$ 形成叔 丁基氨甲基醚(此时, $\mathrm{FeCl}_{2}$ 的作用是促进叔丁基氨甲基 醚中间体的生成); 然后它再与端炔在 $\mathrm{FeCl}_{2}$ 的作用下反
应生成交叉偶联产物(此时, $\mathrm{FeCl}_{2}$ 的作用是诱导叔丁基 氨甲基醚发生 $\mathrm{S}_{\mathrm{N}} 1$ 消除形成亚胺离子)(Scheme 7).

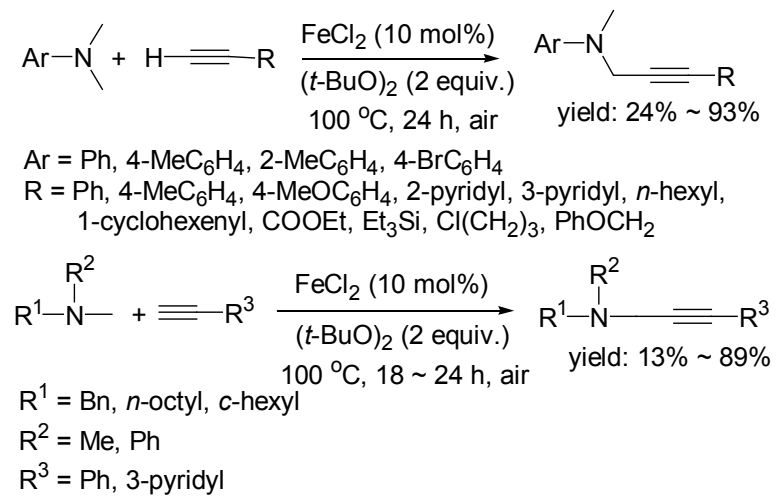

Scheme 6

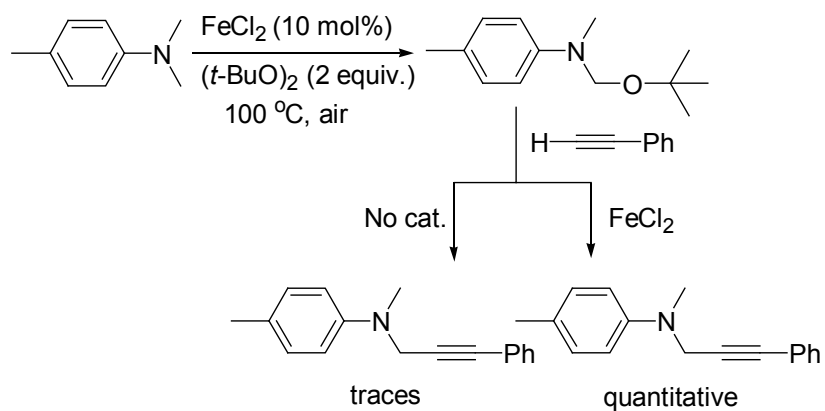

Scheme 7

2010 年, Chen 课题 组 ${ }^{[60]}$ 发现以廉价的 $\mathrm{Fe}(\mathrm{acac})_{3} / \mathrm{Cu}(\mathrm{acac})_{2}$ 作催化体系, 空气作氧化剂, $\mathrm{K}_{2} \mathrm{CO}_{3}$ 作碱在 DMF 中于 $50{ }^{\circ} \mathrm{C}$ 下可以使两种不同当量的末端 基炔发生交叉偶联反应，且反应条件温和，一系列产物 收率在 45\% 74\%之间(Eq. 28). 其中，反应过程中不可 避免地生成炔的自偶联产物，若只使用少量的铜催化 剂，只能得到痕量的交叉偶联产物.

$$
\begin{aligned}
& \mathrm{R}^{1} \rightleftharpoons+\equiv \mathrm{R}^{2} \frac{\begin{array}{c}
\mathrm{Fe}(\mathrm{acac})_{3}(0.1 \text { equiv. }) \\
\mathrm{Cu}(\mathrm{acac})_{2}(0.001 \text { equiv. })
\end{array}}{\mathrm{K}_{2} \mathrm{CO}_{3}(2 \text { equiv. })} \\
& \text { DMF, } 50{ }^{\circ} \mathrm{C} \text {, air } \\
& \mathrm{R}^{1}=\mathrm{R}^{2} \\
& \text { yield: } 45 \% \sim 74 \% \\
& \mathrm{R}^{1}=\mathrm{Ph}, 4-\mathrm{MeOC}_{6} \mathrm{H}_{4} \\
& \mathrm{R}^{2}=4-\mathrm{MeOC}_{6} \mathrm{H}_{4}, 4-n-\mathrm{C}_{5} \mathrm{H}_{11} \mathrm{OC}_{6} \mathrm{H}_{4}, \mathrm{HOCH}_{2}, 2-\mathrm{HO} \text {-propyl, } \\
& \text { 3-Thienyl, 3- } \mathrm{MeC}_{6} \mathrm{H}_{4}
\end{aligned}
$$

2012 年, You 课题组 ${ }^{[61]}$ 报道了 $\mathrm{Fe} / \mathrm{Ag}$ 体系催化芳基 硼酸与端炔的偶联(Eq. 29). 对铁催化剂进行篎选, 结果 发现不加催化剂时, 不发生交叉偶联反应; $\mathrm{FeCl}_{3}$ 比其它 铁盐催化效果要好, 而带结晶水的 $\mathrm{FeCl}_{3} \cdot 6 \mathrm{H}_{2} \mathrm{O}$ 催化效 果更好，说明铁盐中水的存在促进了反应的发生. 该反 应中无机碱的种类和碱的存在与否对反应收率无显著 
影响, 因为 $\mathrm{Ag}_{2} \mathrm{CO}_{3}$ 能促进芳基硼酸的转金属化; 可见 银盐的存在起着至关重要的作用, 不加银盐没有交叉偶 联产物生成. 对反应广普性研究发现带有吸电子基的芳 基硼酸不如含有供电子基或中性基团的芳基硼酸活性 高; 同时, 位阻效应对反应也有很大的影响, 如邻位取 代的芳基硼酸收率相对较低.

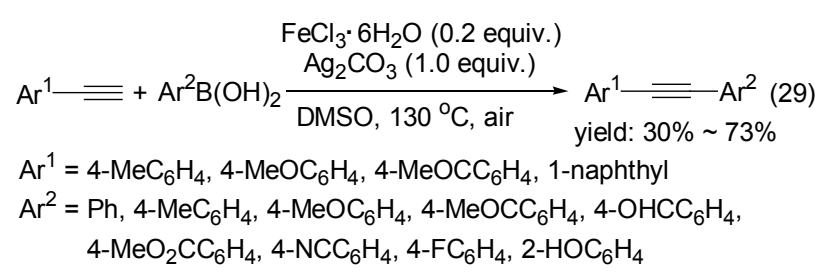

\section{$4 \mathrm{Ni}$ 催化}

2009 年, Lei 课题组 ${ }^{[62]}$ 首次采用廉价的 $\mathrm{NiCl}_{2} \bullet 6 \mathrm{H}_{2} \mathrm{O}$ 代替钯作催化剂, 在 $\mathrm{CuI}$ 存在下, 用 $20 \mathrm{~mol} \%$ TMEDA 作配体, 氧气或空气作氧化剂在 THF 溶剂中于室温条 件下完成了两种端基炔的交叉偶联反应(Eq. 30). 实验 发现当其中一种炔投入量是另一种炔的 5 倍时, 反应 20 $\mathrm{h}$ 后, 两种不同末端炔可有效地发生交叉偶联反应. 反 应广普性研究表明无论是芳香炔还是脂肪炔均以中等 到较好的收率获得产物(60\% 93\%); 更为重要的是, 活泼的芳基碘在很多过渡金属催化反应中都参与反应, 然而在该反应发生的过程中, 得到的产物保留了卤素 碘, 为进一步转化提供了机会.

$$
\begin{aligned}
& \mathrm{R}^{1}=+\bar{\equiv} \mathrm{R}^{2} \frac{\mathrm{NiCl}_{2} \cdot 6 \mathrm{H}_{2} \mathrm{O}, \mathrm{Cul}}{\mathrm{TMEDA}, \mathrm{NEt}_{3}, \mathrm{THF}} \mathrm{R}^{1}=\mathrm{R}^{2} \text { yield: } 60 \% \sim 93 \% \\
& \mathrm{R}^{1}=\mathrm{Ph}, \mathrm{MeOCH}_{2}, \mathrm{AcOCH}_{2} \\
& \mathrm{R}^{2}=\mathrm{MeOCH}_{2}, \mathrm{BnOCH}_{2}, \mathrm{AcOCH}_{2}, \mathrm{HOCH}_{2}, \mathrm{PhHNCH}_{2} \text {, equiv. }
\end{aligned}
$$

2010 年, Miura 课题组 ${ }^{[42]}$ 报道了用 $\mathrm{NiBr}_{2} \bullet$ 二甘醇二 甲醚/4,4'-二叔丁基-2,2'-联吡啶(dtbpy)作催化剂催化唑 类化合物与端基炔的偶联反应(Eq. 31). 该反应体系用 $t$-BuOLi 作碱, 甲苯作溶剂, 在氧气存在下于 $100{ }^{\circ} \mathrm{C}$ 反 应得到交叉偶联产物. 对于一系列芳香与脂肪炔烃, 收 率为 37\% 62\%. 若用极性溶剂和其它叔丁基碱金属作 碱(如 $t$ - BuONa 或 $t$ - BuOK), 则原料易分解. 作者推测该 反应机理如下: 原位生成的 $\mathrm{Ni}(\mathrm{II})$ 配合物 4 在 $t$-BuOLi 的作用下与端炔 $\mathbf{2}$ 反应产生炔镍中间体 $\mathbf{5}$, 紧接着通过 $t$-BuOLi 对唑类化合物 $\mathbf{1}$ 相对显酸性的 $\mathrm{sp}^{2}-\mathrm{C}-\mathrm{H}$ 键的去 质子化反应生成了杂环芳基锂 $\mathbf{6 , 6}$ 再经过与中间体 $\mathbf{5}$ 的 转金属化和还原消除提供了交叉偶联产物 $\mathbf{3}$ 和零价镍配 合物 8. 氧气氧化 8 可产生 4 来完成催化循环. 如果中间
体 5 与端炔 $\mathbf{2}$ 能很好地发生反应，则将会生成二炔产物 (Scheme 8).
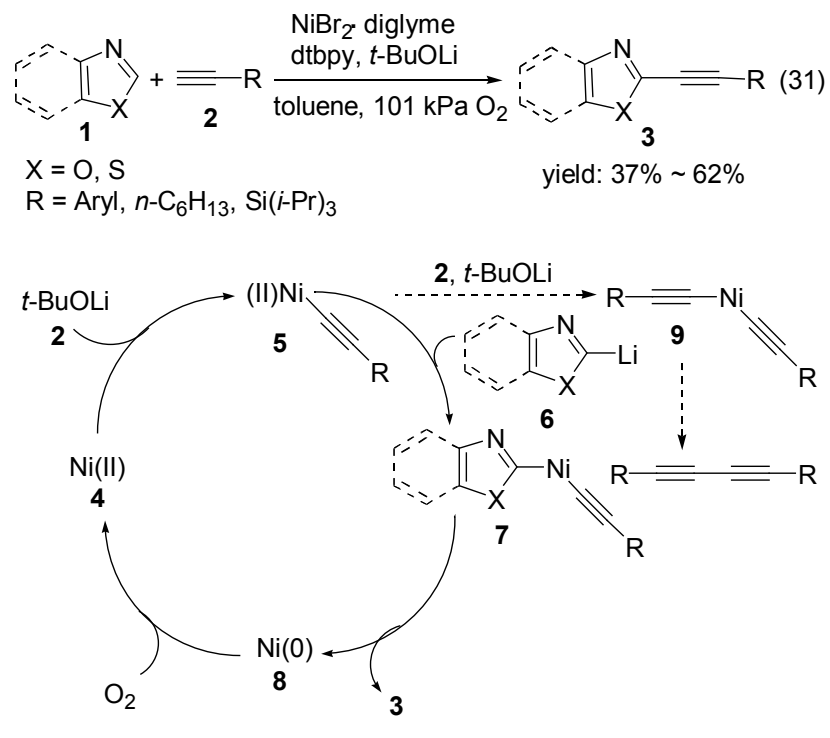

Scheme 8

\section{$5 \mathrm{Ag}$ 催化}

与传统过渡金属催化的偶联反应相比较, 在两个不 同的 $\mathrm{C}-\mathrm{H}$ 或 $\mathrm{X}-\mathrm{H}(\mathrm{X}$ 代表杂原子)之间的直接氧化偶 联具有很大优点, 可以避免反应物预官能化. 在这一新 兴领域里, 有关端炔的高效和高选择性偶联仍具有挑战 性，在氧化偶联反应条件下，不可避免地要生成端炔的 自偶联产物，为了抑制炔的自偶联发生，通常使另一反 应物过量或者使用注射器缓慢滴加炔来达到高选择性 地合成交叉偶联产物. 最近, 直接氧化 $\mathrm{C}-\mathrm{H}$ 官能化/炔 基化已经实现，银盐在高选择性化学合成涉及端炔的反 应中表现出巨大的潜力.

2012 年, Lei 课题组 ${ }^{[63]}$ 报道了碳酸银催化 2-氨基吡 啶化合物与端炔的 $\mathrm{C}-\mathrm{H} / \mathrm{N}-\mathrm{H}$ 氧化偶联/环化合成杂原 子咪唑并 $[1,2-a]$ 吡啶化合物(Eq. 32). 该反应需在 $\mathrm{N}_{2}$ 保 护下于二氧六环中进行, 结果发现各种取代的 2-氨基吡 啶化合物与端炔均以高选择性和较差到中等的收率进 行反应 $(14 \% \sim 77 \%)$, 没有检测到端炔的自偶联副产物. 作者推测该反应机理如下: 首先, 端炔 11a 与 $\mathrm{Ag}(\mathrm{I})$ 反应 生成炔银配合物 $\mathbf{A}$; 然后, 2-氨基吡啶化合物 10a 在银的 作用下对配合物 $\mathbf{A}$ 进行亲核进攻生成重要的中间体 $\mathbf{B}$; 最后，中间体 $\mathbf{B}$ 通过银诱导的氧化环合反应提供了产物 12 (Scheme 9).

$$
\begin{array}{ll}
\mathrm{R}^{1}=\mathrm{Me}, \mathrm{Br}, \mathrm{Cl}, \mathrm{I}, \mathrm{Ph} & \text { yield: } 14 \% \sim 77 \% \\
\mathrm{R}^{2}=\mathrm{Aryl}, \mathrm{CH}_{2} \mathrm{OPiv} & \mathrm{R}^{2} \stackrel{\mathrm{Ag}_{2} \mathrm{CO}_{3} \text {, dioxane }}{\mathrm{N}_{2}, 110{ }^{\circ} \mathrm{C}}
\end{array}
$$




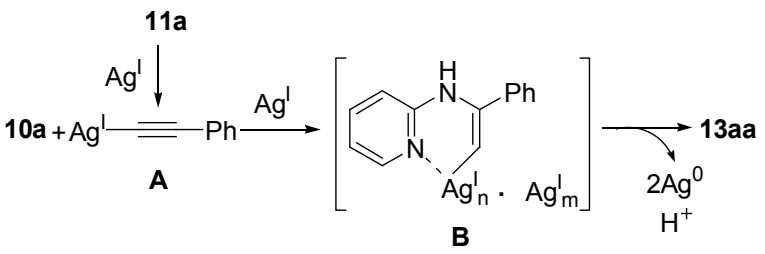

Scheme 9

同年, 该组 ${ }^{[64]}$ 用碳酸银 $\left(\mathrm{Ag}_{2} \mathrm{CO}_{3}\right)$ 作催化剂催化 $1,3-$ 二羰基化合物和端炔高选择性地氧化 $\mathrm{C}-\mathrm{H} / \mathrm{C}-\mathrm{H}$ 功能 基活化来一步合成多取代的呋喃衍生化合物(Eq. 33). 他们认为银在有关炔的 $\mathrm{C}-\mathrm{H}$ 键活化氧化交叉偶联反应 中起着关键促进剂的作用. 底物广普性研究表明大部分 芳香族端炔以中等到较高的收率得到产物 $(60 \% \sim 95 \%)$, 脂肪族的炔如丙-2-炔基新戊酸酯在该反应条件下反应 时产物收率不高 (39\%). 该反应的优点是：(1)催化剂 $\mathrm{Ag}_{2} \mathrm{CO}_{3}$ 可以回收循环利用, 且没有失去活性; (2) 原子经 济性高, 环境污染少; (3)反应条件温和.

$$
\begin{aligned}
& \mathrm{Ar}=\mathrm{R}^{1}=\mathrm{CH}_{3}, \mathrm{Ph}, i-\mathrm{Pr} \\
& \mathrm{R}^{2}=\mathrm{CO}_{2} \mathrm{Et}, \mathrm{CO}_{2} \mathrm{Me}, \mathrm{CO}_{2}-\mathrm{t}-\mathrm{Bu}, \mathrm{CO}_{2} \mathrm{Bn}, \mathrm{CO}_{2} \mathrm{Cy}, \mathrm{COPh}, \mathrm{CO}_{2}-n-\mathrm{C}_{8} \mathrm{H}_{17}
\end{aligned}
$$

\section{$6 \mathrm{Au}$ 催化}

2010 年, Nevado 课题组 ${ }^{[65]}$ 第一次报道了用 $\mathrm{Ph}_{3} \mathrm{PAuCl}$ 作催化剂完成芳烃和端基炔的芳烃炔基化反 应(Eq. 34). 反应体系中用一种有效、绿色的高价碘苯化 合物 $\mathrm{PhI}(\mathrm{OAc})_{2}$ 作氧化剂, $\mathrm{NaHCO}_{3}$ 作碱在 1,2-DCE 溶剂 中于 $90{ }^{\circ} \mathrm{C}$ 下反应. 广普性研究表明: 芳香族和脂肪族 炔基酮均取得了 31\% 72\%的收率，炔基酯也以 $60 \%$ $85 \%$ 的收率获得产物, 而苯乙炔由于自偶联比较严重, 获得交叉偶联产物收率较低( $25 \%)$. 该体系最显著的特 点是 “活性低的” 缺电子炔与富电子的芳烃作为偶联反 应原料大部分可以取得中等收率 $(48 \% \sim 85 \%)$. 作者推 测该反应有两个可能的途径, 这两个途径都起始于炔基

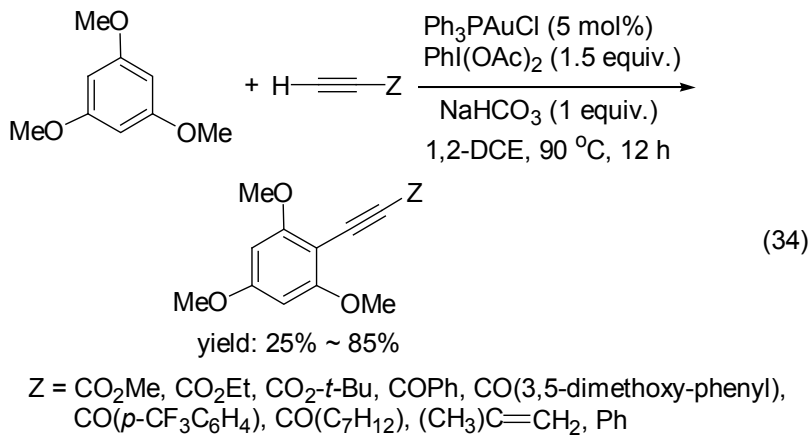

金(I)配合物 $\mathbf{I}$ 的形成, I 在 $\mathrm{PhI}(\mathrm{OAc})_{2}$ 的作用下氧化成炔 金(III)中间体 II，中间体 II 与芳烃通过亲电芳香取代反 应产生另一中间体 III, 最后这一新的中间体III经过还 原消除生成了炔基化产物 $\mathbf{I V}$; 或者配合物 I 与 $\mathrm{PhI}(\mathrm{OAc})_{2}$ 反应生成具有亲电性的炔基碘化合物 $\mathbf{V}$, 然 后芳香环与 $\mathbf{V}$ 中的三键进行加成生成烯基金中间体 $\mathbf{V I}$, 中间体 VI 经过 $\beta$-消除得到产物 IV (Scheme 10).

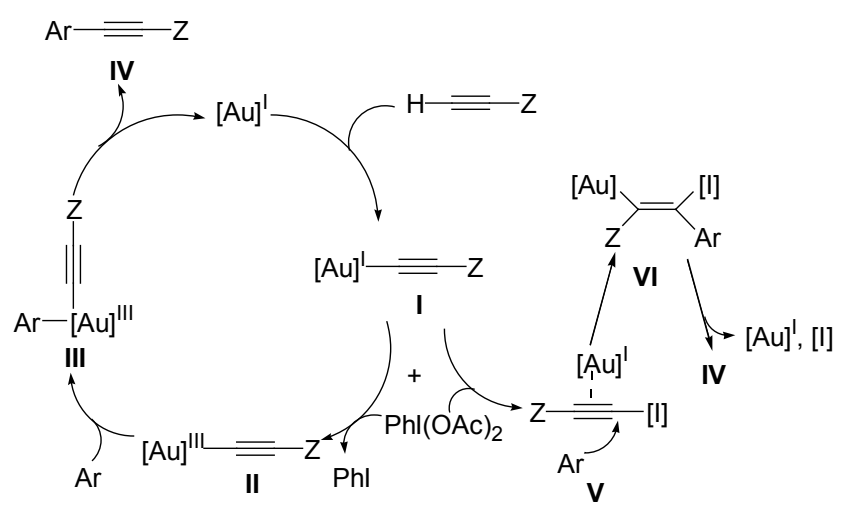

\section{Scheme 10}

\section{7 结论与展望}

本文总结了不同催化体系催化端基炔参与的氧化 交叉偶联反应的一些最新进展，与基于官能团转化的传 统反应相比, 氧化交叉偶联反应具有以下优势: (1)直接 催化活化反应底物中的 $\mathrm{C}-\mathrm{H}$ 键，可以避免制备官能团 化反应底物的额外反应步骤; (2)反应更绿色、更清洁, 尤其是使用氧气作为氧化剂时，反应的副产物就是水; (3)反应更高效，可以减少传统的有机合成步骤，进而提 高有机合成的效率.

氧化交叉偶联反应是高效高选择性的有机合成反 应，为新一代有机合成化学的发展提供了一种新思路; 同时，它也代表了绿色合成化学发展的一个新方向，但 是，同时也应该看到该类反应仍然有诸多问题有待解 决: (1)金属催化剂的研究有待扩展; (2)空气作为最终氧 化剂的研究仍需大力发展; (3)配体和添加剂的种类有待 进一步拓展，其反应机理有待更加深入地探讨; (4)底物 范围相对较窄, 仍需不断扩大.

\section{References}

[1] Ullmann, F. Ber. Dtsch. Chem. Ges. 1903, 36, 2382.

[2] Zhang, B. B.; Zhan, D.; Zhang, X. P.; Xiang, Q. J.; Zeng, Q. L. Acta Chim. Sinica 2012, 70, 1655 (in Chinese).

(张斌涁, 詹丹, 张小平, 向沁洁, 曾庆乐, 化学学报, 2012, 70, 1655.)

[3] Darses, S.; Genet, J. P. Chem. Rev. 2008, 108, 288.

[4] Miyaura, N.; Suzuki, A. Chem. Rev. 1995, 95, 2457.

[5] Alonso, F.; Beletskaya, I. P.; Yus, M. Tetrahedron 2005, 61, 11771. 
[6] (a) Li, X.; Yan, X. Y.; Chang, H. H.; Wang, L. C.; Zhang, Y.; Chen, W. W.; Li, Y. W.; Wei, W. L. Org. Biomol. Chem. 2012, 10, 495.

(b) Li, X.; Wang, L. C.; Chang, H. H.; Zhang, C. X.; Wei, W. L. Appl. Catal. A: Gen. 2013, 462 463, 15.

[7] Wen, Y. M.; Jiang, H. F. Acta Chim. Sinica 2012, 70, 1716 (in Chinese). (温燕梅, 江焕峰, 化学学报, 2012, 70, 1716.)

[8] Ritleng, V.; Sirlin, C.; Pfeffer, M. Chem. Rev. 2002, 102, 1731.

[9] Arockiam, P. B.; Bruneau, C.; Dixneuf, P. H. Chem. Rev. 2012, $112,5879$.

[10] Jia, C. G.; Kitamura, T.; Fujiwara, Y. Acc. Chem. Res. 2001, 34, 633.

[11] Li, H.; Li, B. J.; Shi, Z. J. Catal. Sci. Technol. 2011, 1, 191.

[12] (a) Pan, F.; Shi, Z. J. Acta Chim. Sinica 2012, 70, 1679 (in Chinese).

(潘菲, 施章杰, 化学学报, 2012, 70, 1679.)

(b) Zhang, D.; Qin, Y. Acta Chim. Sinica 2013, 71, 147 (in Chinese).

(张丹, 秦勇, 化学学报, 2013, 71, 147.)

[13] Li, C. J. Acc. Chem. Res. 2009, 42, 335.

[14] Li, Z. P.; Li, C. J. J. Am. Chem. Soc. 2005, 127, 3672.

[15] Cai, G. X.; Fu, Y.; Li, Y. Z.; Wan, X. B.; Shi, Z. J. J. Am. Chem. Soc. 2007, 129, 7666.

[16] Huber, S. M.; Ertem, M. Z.; Aquilante, F.; Gagliardi, L.; Tolman, W. B.; Cramer, C. J. Chem. Eur. J. 2009, 15, 4886.

[17] Sonogashira, K. J. Organomet. Chem. 2002, 653, 46.

[18] Glaser, C. Ber. Dtsch. Chem. Ges. 1869, 2, 422.

[19] Glaser, C. Ann. Chem. Pharm. 1870, 154, 137.

[20] Kim, S. H.; Yoon, J.; Chang, S. Org. Lett. 2011, 13, 1474.

[21] Liang, B.; Dai, M. J.; Chen, J. H.; Yang, Z. J. Org. Chem. 2005, 70, 391.

[22] Li, J. H.; Liang, Y.; Xie, Y. X. J. Org. Chem. 2005, 70, 4393.

[23] Hadi, V.; Yoo, K. S.; Jeong, M.; Jung, K. W. Tetrahedron Lett. 2009, 50, 2370.

[24] Chen, M.; Zheng, X. L.; Li, W. Q.; He, J.; Lei, A. W. J. Am. Chem. Soc. 2010, 132, 4101.

[25] Luh, T. Y.; Leung, M. K.; Wong, K. T. Chem. Rev. 2000, 100, 3187.

[26] Facoetti, D.; Abbiati, G.; d'Avolio, L.; Ackermann, L.; Rossi, E. Synlett 2009, 2273.

[27] Yue, D. W.; Larock, R. C. Org. Lett. 2004, 6, 1037.

[28] Zhang, H. M.; Larock, R. C. J. Org. Chem. 2002, 67, 7048.

[29] Gu, Y. H.; Wang, X. M. Tetrahedron Lett. 2009, 50, 763.

[30] Besselièvre, F.; Piguel, S. Angew. Chem., Int. Ed. 2009, 48, 9553.

[31] Brand, J. P.; Charpentier, J.; Waser, J. Angew. Chem., Int. Ed. 2009, 48, 9346.

[32] Yang, L.; Zhao, L.; Li, C. J. Chem. Commun. 2010, 46, 4184.

[33] Zou, G.; Zhu, J. R.; Tang, J. Tetrahedron Lett. 2003, 44, 8709.

[34] Yang, F.; Wu, Y. J. Eur. J. Org. Chem. 2007, 3476.

[35] Ye, Z. S.; Liu, M. C.; Lin, B. D.; Wu, H. Y.; Ding, J. C.; Cheng, J.
Tetrahedron Lett. 2009, 50, 530.

[36] Wu, C. R.; Li, P.; Fang, Y. S.; Zhao, J. J.; Xue, W. C.; Li, Y.; Larock, R. C.; Shi, F. Tetrahedron Lett. 2011, 52, 3797.

[37] Jie, X. M.; Shang, Y. P.; Hu, P.; Su, W. P. Angew. Chem., Int. Ed. 2013, 52, 3535.

[38] Zhou, L.; Ye, F.; Ma, J. C.; Zhang, Y.; Wang, J. B. Angew. Chem., Int. Ed. 2011, 50, 3510.

[39] Hamada, T.; Ye, X.; Stahl, S. S. J. Am. Chem. Soc. 2008, 130, 833.

[40] Wang, L.; Huang, H.; Priebbenow, D. L.; Pan, F. F.; Bolm, C. Angew. Chem., Int. Ed. 2013, 52, 3478.

[41] Wei, Y.; Zhao, H. Q.; Kan, J.; Su, W. P.; Hong, M. C. J. Am. Chem. Soc. 2010, 132, 2522.

[42] Matsuyama, N.; Kitahara, M.; Hirano, K.; Satoh, T.; Miura, M. Org. Lett. 2010, 12, 2358.

[43] Iorga, B.; Eymery, F.; Carmichael, D.; Savignac, P. Eur. J. Org. Chem. 2000, 3103.

[44] Lera, M.; Hayes, C. J. Org. Lett. 2000, 2, 3873.

[45] Gao, Y. X.; Wang, G.; Chen, L.; Xu, P. X.; Zhao, Y. F.; Zhou,Y. B.; Han, L. B. J. Am. Chem. Soc. 2009, 131, 7956.

[46] Kitahara, M.; Hirano, K.; Tsurugi, H.; Satoh, T.; Miura, M. Chem. Eur. J. 2010, 16, 1772.

[47] Chu, L. L.; Qing, F. L. J. Am. Chem. Soc. 2010, 132, 7262.

[48] Li, Z. P.; Li, C. J. J. Am. Chem. Soc. 2004, 126, 11810.

[49] Zhao, L.; Li, C. J. Angew. Chem., Int. Ed. 2008, 47, 7075.

[50] Bi, H. P.; Zhao, L.; Liang, Y. M.; Li, C. J. Angew. Chem., Int. Ed. 2009, 48, 792.

[51] Niu, M. Y.; Yin, Z. M.; Fu, H.; Jiang, Y. Y.; Zhao, Y. F. J. Org. Chem. 2008, 73, 3961.

[52] Pan, C. D.; Luo, F.; Wang, W. H.; Ye, Z. S.; Cheng, J. Tetrahedron Lett. 2009, 50, 5044.

[53] Jiang, X. L.; Chu, L. L.; Qing, F. L. Org. Lett. 2012, 14, 2870.

[54] Xu, X. L.; Li, X. N. Org. Lett. 2009, 11, 1027.

[55] Xu, Z. W.; Yu, X. Q.; Feng, X. J.; Bao, M. J. Org. Chem. 2011, 76, 6901.

[56] Stavropoulos, P.; Çelenligil-Çetin, R.; Tapper, A. E. Acc. Chem. Res. 2001, 34, 745.

[57] Walling, C. Acc. Chem. Res. 1998, 31, 155.

[58] Volla, C. M. R.; Vogel, P. Org. Lett. 2009, 11, 1701.

[59] (a) Horner, L.; Junkermann, H. Ann. Chem. Justus Liebig 1955, $591,53$.

(b) Horner, L.; Kirmse, W. Ann. Chem. Justus Liebig 1955, 597, 48.

[60] Meng, X.; Li, C. B.; Han, B. C.; Wang, T. S.; Chen, B. H. Tetrahedron 2010, 66, 4029.

[61] You, X. L.; Xu, L.; Hu, T. Lett. Org. Chem. 2012, 9, 300.

[62] Yin, W. Y.; He, C.; Chen, M.; Zhang, H.; Lei, A. W. Org. Lett. 2009, 11, 709.

[63] He, C.; Hao, J.; Xu, H.; Mo, Y. P.; Liu, H. Y.; Han, J. J.; Lei, A. W. Chem. Commun. 2012, 48, 11073.

[64] He, C.; Guo, S.; Ke, J.; Hao, J.; Xu, H.; Chen, H. Y.; Lei, A. W. J. Am. Chem. Soc. 2012, 134, 5766.

[65] de Haro, T.; Nevado, C. J. Am. Chem. Soc. 2010, 132, 1512.

(Cheng, F.) 